\title{
DYNAMIC BEHAVIOR OF FRAMED STRUCTURES WITH AN ELASTIC INTERNAL HINGE
}

\author{
A. R. Ratazzi ${ }^{1}$, D. V. Bambill ${ }^{1,2}$, C. A. Rossit ${ }^{1,2}$ \\ ${ }^{1}$ Instituto de Mecánica Aplicada (IMA), Departmento de Ingeniería, Universidad Nacional del \\ Sur (UNS), Argentina. (alejandro.ratazzi@ uns.edu.ar, dbambill@ criba.edu.ar, caros- \\ sit@criba.edu.ar )
}

${ }^{2}$ Consejo Nacional de Investigaciones Científicas y Técnicas (CONICET), Argentina.

\begin{abstract}
The study of the dynamic properties of framed structures is extremely important in the field of structural engineering. In this paper the first natural frequencies of transverse vibration of frames are determined. The elastic structural system consists of a beam supported by a column. The presence of an internal hinge located in different positions of the beam is considered. The hinge is elastically restrained against rotation and translation. Attention is given to the way in which supports are modeled. It is known that ideal supports used in many structural models do not fit exactly with the real supports. Here the column is considered not rigidly connected to the foundation. The displacement of the component elements are assumed to be described by the theory of Euler-Bernoulli. The governing equations of the system, together with the boundary and compatibility conditions are obtained using the technique of variational calculus. Applying the method of separation of variables, the exact values of the natural frequencies of the model are obtained. Results are given for different cases, which arise from combining different magnitudes in the internal elastic hinge. These results are compared with those obtained using the finite element method, and in particular cases they are also compared with values available in the literature. Finally, an experimental device allows verifying the procedure.
\end{abstract}

Keywords: Vibration, Frame, Modal shapes, Elastically supported, Hinge.

\section{INTRODUCTION}

As Laura et al. pointed in [1], many excellent books and technical papers deal with vibrating frames, such as Warburton [2], Blevins [3], Clough and Penzien [4], Timoshenko and Young [5], Karnosky and Lebed [6], among others. The title problem is of importance in practically all fields of engineering given that frame structures resist by virtue of its geometry, ranging from big scale like bridges and buildings placed in seismically active regions, to micro-frames used in modern electronic equipment subject to vibratory environments.

Many researchers have analyzed the vibration of frames. Lin and Ro [7] proposed a hybrid analytical/numerical method to do dynamic analysis of planar serial-frame structures. $\mathrm{Wu}$ [8] presented an elastic-and-rigid-combined beam element to determine the dynamic characteristics of a two-dimensional frame composed of any number of beam segments. In his paper Mei [9] considered the vibration in multi-story planar frame structures from the wave 
vibration standpoint. Laura et al. [1] determined the in-plane vibration of frames with concentrated masses attached and Filipich and Laura [10] analyzed in-plane vibrations of portal frames with elastically restrained ends. An approximate solution is obtained by means of a variational method.

In the particular case of L-frame structures, early studies have been done by Bang [11], Grügöze[12] and Oguamanam et al. [13]. In 2003 Heppler et al. [14] extend the previous paper [13] by relaxing the restrictions on the motion of the open frame. In 2005 Abarracín and Grossi [15] determined natural frequencies and mode shapes of elastically restrained L-frames. They applied the separation of variables method for the determination of the exact eigenfrequencies and mode shapes and calculated the eigenvalues numerically by applying the Newton method strategy to the corresponding frequency equation. Lee and $\mathrm{Ng}$ [16] used a formulation by the Rayleigh-Ritz method together with the introduction of artificial linear and torsional springs for computing the natural frequencies and modes for the in-plane vibrations of complex planar frame structures.

The presence of an internal hinge in beams has been treated in several papers by Wang and Wang [17], Lee et al. [18], Chang et al. [19], Grossi and Quintana [20], Quintana et al. [21]. Here, we deal with the vibration of L-frames assuming an internal hinge in different positions of the horizontal part of the frame. The two members of the L-shaped geometry are joined at right angle, with the end of one of them clamped and the end of the other elastically restrained. Figure 1 depicts the structure under study.

The presence of the hinge allows the simulation of a crack model as developed by Chondros et al. [22], and some numerical experiments are included. It is assumed that the beams are adequately modeled using Euler -Bernoulli theory and the method of separation of variables is used to obtain the exact values of the natural frequencies of the model.

Numerical results are obtained for different magnitudes of the internal elastic hinge and the boundary conditions by means of MATHEMATICA [23] code. These results are compared with results obtained with the finite element method in ALGOR [24]. Additionally, some particular cases are compared with values available in the literature and experimental results.

\section{THEORY AND FORMULATIONS}

The L-frame under study has elastic restrain and clamped ends as shown in Figure 1. The structure is composed of three members, a vertical beam (column) of length $l_{1}$ and two consecutive horizontal beams of lengths $l_{2}$ and $l_{3}$ respectively (see Figure 1). At the intermediate point, the horizontal beams have an internal hinge elastically restrained against rotation between them and the hinge is externally restrained by translational and rotational springs. 


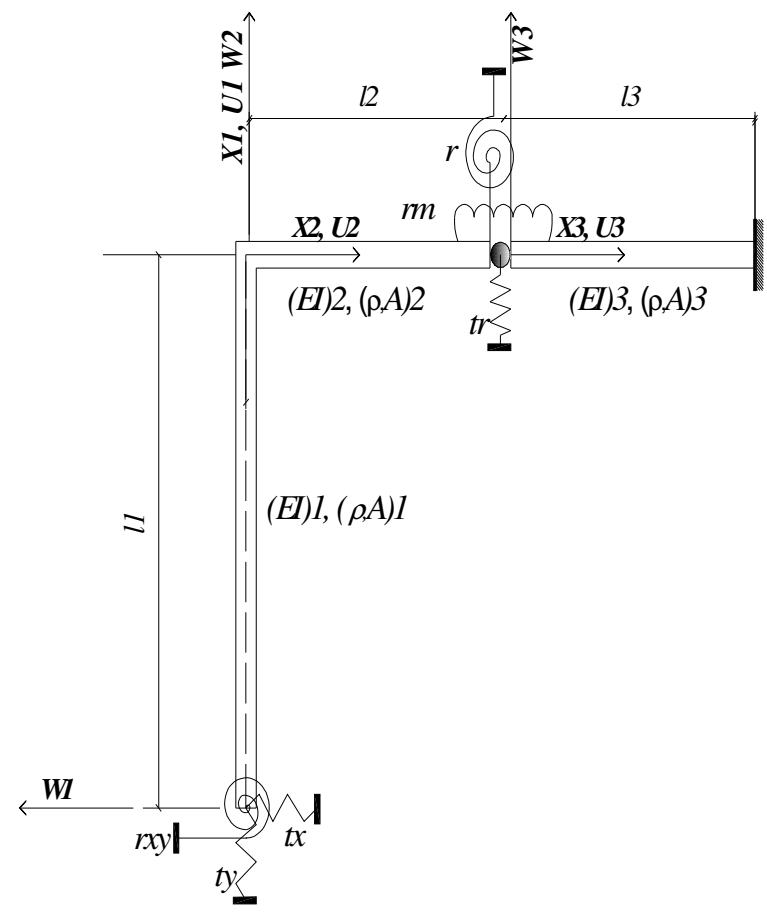

Figure 1. L-frame structure.

The rotational restraints are characterized by the spring constants $r x y, r$ and $r m$. and the translational restraints by the spring constants $t x$, ty and $t r$. The behaviors of the individual members of the frames are assumed to be governed by Euler-Bernulli beam theory and the axial deformation effects are also included.

For this case let us consider a three-element frame, $i=1,2,3$. The transverse and axial displacements are described by the functions:

$$
\begin{aligned}
& W_{i}=W_{i}\left(X_{i}, t\right) ; i=1,2,3 . \\
& U_{i}=U_{i}\left(X_{i}, t\right), i=1,2,3 .
\end{aligned}
$$

The kinetic energy of the mechanical system, at time $t$, is given by:

$$
\begin{aligned}
T= & \frac{1}{2} \int_{0}^{l_{1}}(\rho A)_{1}\left[\left(\frac{\partial W_{1}}{\partial t}\left(X_{1}, t\right)\right)^{2}+\left(\frac{\partial U_{1}}{\partial t}\left(X_{1}, t\right)\right)^{2}\right] d X \\
& +\frac{1}{2} \int_{0}^{l_{2}}(\rho A)_{2}\left[\left(\frac{\partial W_{2}}{\partial t}\left(X_{2}, t\right)\right)^{2}+\left(\frac{\partial U_{2}}{\partial t}\left(X_{2}, t\right)\right)^{2}\right] d X \\
& +\frac{1}{2} \int_{0}^{l_{3}}(\rho A)_{3}\left[\left(\frac{\partial W_{3}}{\partial t}\left(X_{3}, t\right)\right)^{2}+\left(\frac{\partial U_{3}}{\partial t}\left(X_{3}, t\right)\right)^{2}\right] d X
\end{aligned}
$$

where $(\rho A)_{i}$ denotes the mass per unit length of the members of the frame. 
On the other hand, the potential energy of the mechanical system is given by:

$$
\begin{aligned}
U= & \frac{1}{2} \int_{0}^{l_{1}}\left[(E I)_{1}\left(\frac{\partial^{2} W_{1}}{\partial X_{1}^{2}}\left(X_{1}, t\right)\right)^{2}+(E A)_{1}\left(\frac{\partial U_{1}}{\partial X_{1}}\left(X_{1}, t\right)\right)^{2}\right] d X_{1} \\
& +\frac{1}{2} \int_{0}^{l_{2}}\left[(E I)_{2}\left(\frac{\partial^{2} W_{2}}{\partial X_{2}^{2}}\left(X_{2}, t\right)\right)^{2}+(E A)_{2}\left(\frac{\partial U_{2}}{\partial X_{2}}\left(X_{2}, t\right)\right)^{2}\right] d X_{2} \\
& +\frac{1}{2} \int_{0}^{l_{3}}\left[(E I)_{3}\left(\frac{\partial^{2} W_{3}}{\partial X_{3}^{2}}\left(X_{3}, t\right)\right)^{2}+(E A)_{3}\left(\frac{\partial U_{3}}{\partial X_{3}}\left(X_{3}, t\right)\right)^{2}\right] d X_{3} \\
& +\frac{r}{2}\left(\frac{\partial W_{2}}{\partial X_{2}}\left(l_{2}, t\right)\right)^{2}+\frac{t r}{2}\left(W_{2}\left(l_{2}, t\right)\right)^{2}+r m\left(\frac{\partial W_{2}\left(l_{2}, t\right)}{\partial X_{2}}-\frac{\partial W_{3}(0, t)}{\partial X_{3}}\right)^{2}+ \\
& \frac{r x y}{2}\left(\frac{\partial W_{1}}{\partial X_{1}}(0, t)\right)^{2}+\frac{t x}{2}\left(U_{1}(0, t)\right)^{2}+\frac{t y}{2}\left(W_{1}(0, t)\right)^{2} ;
\end{aligned}
$$

where $l_{i},(\rho A)_{i}$ and $(E I)_{i}$ denote the length, the flexural rigidity and the axial rigidity that correspond to each member $i$ of the frame.

It is convenient to introduce dimensionless variables:

$$
x_{i}=X_{i} / l_{i} ; i=1,2,3 ; \text { with } x_{i} \in[0,1] \forall i=1,2,3 .
$$

$W_{i}$ and $U_{i}$ may be expressed in terms of the dimensionless coordinates:

$$
w_{i}=\frac{W_{i}(x, t)}{l_{i}}, i=1,2,3, \quad x \in[0,1], \quad u_{i}=\frac{U_{i}(x, t)}{l_{i}}, i=1,2,3, \quad x \in[0,1] ;
$$

and it is useful to define the following dimensionless parameters:

$$
\begin{gathered}
v_{l i}=\frac{l_{i}}{l}, \quad v_{E I i}=\frac{(E I)_{i}}{E I}, \quad v_{\rho A i}=\frac{(\rho A)_{i}}{\rho A}, i=1,2,3 ; \\
R=\frac{r \times l}{E I} ; R m=\frac{r m \times l}{E I} ; \operatorname{Tr}=\frac{t r \times l^{3}}{E I} ; \\
R x y=\frac{r x y \times l}{E I} ; T x=\frac{t x \times l^{3}}{E I} ; T y=\frac{t y \times l^{3}}{E I} ;
\end{gathered}
$$

with $l=l_{1} ; E=E_{1} ; \rho=\rho_{1} ; A=A_{1} ; I=I_{1}$;

where $l,(\rho A)$ and $(E I)$ correspond to the characteristics of the member 1 of the frame. 


\section{1 Expression of the functional}

Hamilton's principle requires that between times $t_{a}$ and $t_{b}$, at which the positions of the mechanical system are known, the system should execute a motion which makes the functional stationary on the space of admissible functions

$$
J(\boldsymbol{w})=\int_{t_{a}}^{t_{b}}(T-U) d t,
$$

where $\boldsymbol{w}=\left(w_{i}, u_{i}\right)$.

The stationary condition required by Hamilton's principle is given by:

$$
\delta J(w, v)=0, \forall v \in D_{0} ;
$$

where $D_{0}$ is a space of admissible direction at $\boldsymbol{w}$ for the domain $D$ of the functional.

Then, the expression of the functional is:

$$
\begin{aligned}
& J(w)=\frac{1}{2}\left\{\int_{t_{1}}^{t_{2}} B_{1} \int_{0}^{1}\left[\left(\frac{\partial w_{1}}{\partial t}\left(x_{1}, t\right)\right)^{2}+\left(\frac{\partial u_{1}}{\partial t}\left(x_{1}, t\right)\right)^{2}\right] d x_{2}\right. \\
& +B_{2} \int_{0}^{1}\left[\left(\frac{\partial w_{2}}{\partial t}\left(x_{2}, t\right)\right)^{2}+\left(\frac{\partial u_{2}}{\partial t}\left(x_{2}, t\right)^{2}\right] d x_{2}\right. \\
& \left.+B_{3} \int_{0}^{1}\left[\left(\frac{\partial w_{3}}{\partial t}\left(x_{3}, t\right)\right)^{2}+\left(\frac{\partial u_{3}}{\partial t}\left(x_{3}, t\right)\right)^{2}\right] d x_{3}\right\} d t- \\
& -\frac{1}{2}\left\{\int_{t_{1}}^{t_{2}} C_{1} \int_{0}^{1}\left[\left(\frac{\partial^{2} w_{1}}{\partial x_{1}{ }^{2}}\left(x_{1}, t\right)\right)^{2}+\left(\frac{\partial w_{1}}{\partial x_{1}}\left(x_{1}, t\right)\right)^{2}\right] d x_{1}\right. \\
& +C_{2} \int_{0}^{1}\left[\left(\frac{\partial^{2} w_{2}}{\partial x_{2}{ }^{2}}\left(x_{2}, t\right)\right)^{2}+\left(\frac{\partial u_{2}}{\partial x_{2}}\left(x_{2}, t\right)\right)^{2}\right] d x_{2} \quad ; \\
& \left.+C_{3} \int_{0}^{1}\left[\left(\frac{\partial^{2} w_{3}}{\partial x_{3}{ }^{2}}\left(x_{3}, t\right)\right)^{2}+\left(\frac{\partial u_{3}}{\partial x_{3}}\left(x_{3}, t\right)\right)^{2}\right] d x_{3}\right\} d t- \\
& -\frac{1}{2}\left[C_{2} R \int_{t_{0}}^{t_{1}}\left(\frac{\partial w_{2}}{\partial x_{2}}(1, t)\right)^{2} d t+D_{2} \operatorname{Tr} \int_{t_{0}}^{t_{1}} w_{2}^{2}(1, t) d t\right. \\
& +C_{2} R_{m} \int_{t_{0}}^{t_{1}}\left(\frac{\partial w_{2}}{\partial x_{2}}(1, t)-\frac{\partial w_{3}}{\partial x_{3}}(0, t)\right)^{2} d t+ \\
& C_{1} R_{x y} \int_{t_{0}}^{t_{1}}\left(\frac{\partial w_{1}}{\partial x_{1}}(0, t)\right)^{2} d t+D_{1} T x \int_{t_{0}}^{t_{1}} u_{1}(0, t) d t+ \\
& \left.D_{1} T_{y} \int_{t_{0}}^{t_{1}} w_{1}(0, t) d t\right]
\end{aligned}
$$

where 


$$
B_{i}=\rho A l \times v_{\rho A i} \times v_{l i}, C_{i}=\frac{E I}{l^{3}} \times \frac{v_{E I i}}{\left(v_{l i}\right)^{3}}, D_{i}=\frac{E A}{l} \times \frac{v_{E A i}}{v_{l i}} ; i=1,2,3 .
$$

Taking into account the boundary conditions at the ends, the compatibility and equilibrium conditions at the joints between column and beam, and the compatibility and equilibrium conditions at the two horizontal beams, and applying the procedure of calculus of variations in Eq. 3, the following boundary and eigenvalue problem is obtained:

$$
\begin{gathered}
\frac{\partial^{4} w_{1}}{\partial x_{1}{ }^{4}}\left(x_{1}, t\right)+k_{1}^{4} \frac{\partial^{2} w_{1}}{\partial t^{2}}\left(x_{1}, t\right)=0, \quad k_{1}^{4}=a^{4} \frac{(\rho A)_{1}}{(\rho A l)} \frac{E I}{(E I)_{1}}\left(\frac{l_{1}}{l}\right)^{4} ; \\
\frac{\partial^{2} u_{1}}{\partial x_{1}{ }^{2}}\left(x_{1}, t\right)-p_{1}^{2} \frac{\partial^{2} u_{1}}{\partial t^{2}}\left(x_{1}, t\right)=0, \quad p_{1}^{2}=a^{4} \frac{(\rho A)_{1}}{(\rho A l)} \frac{E I}{(E I)_{1}} \frac{I}{A l^{2}}\left(\frac{l_{1}}{l}\right)^{2} ; \\
\frac{\partial^{4} w_{2}}{\partial x_{2}{ }^{4}}\left(x_{2}, t\right)+k_{2}^{4} \frac{\partial^{2} w_{2}}{\partial t^{2}}\left(x_{2}, t\right)=0, \quad k_{2}^{4}=a^{4} \frac{(\rho A)_{2}}{(\rho A l)} \frac{E I}{(E I)_{2}}\left(\frac{l_{2}}{l}\right)^{4} ; \\
\frac{\partial^{2} u_{2}}{\partial x_{2}{ }^{2}}\left(x_{2}, t\right)-p_{2}^{2} \frac{\partial^{2} u_{2}}{\partial t^{2}}\left(x_{2}, t\right)=0, \quad p_{2}^{2}=a^{4} \frac{(\rho A)_{2}}{(\rho A l)} \frac{E I}{(E I)_{2}} \frac{I}{A l^{2}}\left(\frac{l_{2}}{l}\right)^{2} ; \\
\frac{\partial^{4} w_{3}}{\partial x_{3}{ }^{4}}\left(x_{3}, t\right)+k_{3}^{4} \frac{\partial^{2} w_{3}}{\partial t^{2}}\left(x_{3}, t\right)=0, \quad k_{3}^{4}=a^{4} \frac{(\rho A)_{3}}{(\rho A l)} \frac{E I}{(E I)_{3}}\left(\frac{l_{3}}{l}\right)^{4} ; \\
\frac{\partial^{2} u_{3}}{\partial x_{3}^{2}}\left(x_{3}, t\right)-p_{3}^{2} \frac{\partial^{2} u_{2}}{\partial t^{2}}\left(x_{2}, t\right)=0, \quad p_{3}^{2}=a^{4} \frac{(\rho A)_{3}}{(\rho A l)} \frac{E I}{(E I)_{3}} \frac{I}{A l^{2}}\left(\frac{l_{3}}{l}\right)^{2} ;
\end{gathered}
$$

where $a^{4}=(\rho A / E I) l^{4}$.

$$
\begin{gathered}
E A_{1} \frac{\partial u_{1}}{\partial x_{1}}(0, t)=-t x \times u_{1}(0, t) \\
R x y \frac{\partial w_{1}}{\partial x_{1}}(0, t)=\frac{\partial^{2} w_{1}}{\partial x^{2}}(0, t) \\
\frac{\partial^{3} w_{1}}{\partial x^{3}}(0, t)=t y \times w_{1} \\
w_{1}(1, t)=-u_{2}(0, t) \\
u_{1}(1, t)=w_{2}(0, t)
\end{gathered}
$$




$$
\begin{aligned}
& \frac{\partial w_{1}}{\partial x}(1, t)=\left(\frac{l_{1}}{l_{2}}\right) \frac{\partial w_{2}}{\partial x}(0, t) \\
& \frac{E I_{1}}{l_{1}^{2}} \frac{\partial^{2} w_{1}}{\partial x}(1, t)=\frac{E I_{2}}{l_{2}^{2}} \frac{\partial^{2} w_{2}}{\partial x}(0, t) \\
& E I_{1} \frac{\partial^{3} w_{1}}{\partial x}(1, t)=-E A_{2} \frac{\partial u_{2}}{\partial x}(0, t) \\
& E I_{2} \frac{\partial^{3} w_{2}}{\partial x}(0, t)=E A_{1} \frac{\partial u_{1}}{\partial x}(1, t) \\
& u_{2}(1, t)=u_{3}(0, t) \\
& w_{2}(1, t)=w_{3}(0, t) \\
& R m\left(\frac{\partial w_{2}}{\partial x_{2}}(1, t)-\frac{\partial w_{3}}{\partial x_{3}}(0, t)\right)-R \frac{\partial w_{2}}{\partial x_{2}}(1, t)=\frac{\partial^{2} w_{2}}{\partial x_{2}{ }^{2}}(1, t) \\
& R m\left(\frac{\partial w_{2}}{\partial x_{2}}(1, t)-\frac{\partial w_{3}}{\partial x_{3}}(0, t)\right)=\frac{\partial^{2} w_{3}}{\partial x_{3}^{2}}(0, t) \\
& R \frac{\partial w_{2}}{\partial x_{2}}(1, t)=\frac{\partial^{2} w_{2}}{\partial x_{2}{ }^{2}}(1, t)-\frac{\partial^{2} w_{3}}{\partial x_{3}{ }^{2}}(0, t) \\
& \left(\frac{\partial^{3} w_{2}}{\partial x_{2}{ }^{3}}(1, t)-\frac{\partial^{3} w_{3}}{\partial x_{3}{ }^{3}}(0, t)\right)=\operatorname{Tr} w_{2}(1, t) \\
& \frac{\partial w_{3}}{\partial x}(1, t)=0 \\
& w_{3}(1, t)=0 \text {; } \\
& u_{3}(1, t)=0 \text { ； }
\end{aligned}
$$




\subsection{Determination of the exact solution}

Using the well-known separation of variables method, solution of Eqs. (4) to (9) are assumed to be of the form:

$$
\begin{aligned}
& w_{1}\left(x_{1}, t\right)=\sum_{n=1}^{\infty} w_{1 n}\left(x_{1}\right) T(t) ; \\
& u_{1}\left(x_{1}, t\right)=\sum_{n=1}^{\infty} u_{1 n}\left(x_{1}\right) T(t) ; \\
& w_{2}\left(x_{2}, t\right)=\sum_{n=1}^{\infty} w_{2 n}\left(x_{2}\right) T(t) ; \\
& u_{2}\left(x_{2}, t\right)=\sum_{n=1}^{\infty} u_{2 n}\left(x_{2}\right) T(t) ; \\
& w_{3}\left(x_{3}, t\right)=\sum_{n=1}^{\infty} w_{3 n}\left(x_{3}\right) T(t) ; \\
& u_{3}\left(x_{3}, t\right)=\sum_{n=1}^{\infty} u_{3 n}\left(x_{3}\right) T(t) .
\end{aligned}
$$

The functions $w_{1}, w_{2}, w_{3}, u_{1}, u_{2}$ and $u_{3}$ represent the corresponding transverse and longitudinal modes of natural vibration of each member and are given by:

$$
\begin{gathered}
w_{1 n}\left(x_{1}\right)=c_{1} \cosh \left(\lambda \alpha_{1} x_{1}\right)+c_{2} \operatorname{senh}\left(\lambda \alpha_{1} x_{1}\right)+c_{3} \cos \left(\lambda \alpha_{1} x_{1}\right)+c_{4} \operatorname{sen}\left(\lambda \alpha_{1} x_{1}\right) ; \\
u_{1 n}\left(x_{1}\right)=c_{5} \cos \left(\lambda^{2} \beta_{1} x_{1}\right)+c_{6} \operatorname{sen}\left(\lambda^{2} \beta_{1} x_{1}\right) ; \\
w_{2 n}\left(x_{2}\right)=c_{7} \cosh \left(\lambda \alpha_{2} x_{2}\right)+c_{8} \operatorname{senh}\left(\lambda \alpha_{2} x_{2}\right)+c_{9} \cos \left(\lambda \alpha_{2} x_{2}\right)+c_{10} \operatorname{sen}\left(\lambda \alpha_{2} x_{2}\right) ; \\
u_{2 n}\left(x_{2}\right)=c_{11} \cos \left(\lambda^{2} \beta_{2} x_{2}\right)+c_{12} \operatorname{sen}\left(\lambda^{2} \beta_{2} x_{2}\right) \\
w_{3 n}\left(x_{2}\right)=c_{13} \cosh \left(\lambda \alpha_{3} x_{2}\right)+c_{14} \operatorname{senh}\left(\lambda \alpha_{3} x_{2}\right)+c_{15} \cos \left(\lambda \alpha_{3} x_{2}\right)+c_{16} \operatorname{sen}\left(\lambda \alpha_{3} x_{2}\right) \\
u_{3 n}\left(x_{3}\right)=c_{17} \cos \left(\lambda^{2} \beta_{3} x_{3}\right)+c_{18} \operatorname{sen}\left(\lambda^{2} \beta_{3} x_{3}\right)
\end{gathered}
$$

where:

$$
\alpha_{i}=\sqrt[4]{\frac{v_{\rho A i}}{v_{E I i}}} v_{l i} ; \beta_{i}=\sqrt[4]{\frac{v_{\rho A i}}{v_{E A i}} \frac{I}{A l^{2}}} \quad v_{l i} ; \quad i=1,2,3 .
$$

Finally the natural frequency coefficients of the vibrating system in the adimentional form is expressed: 


$$
\lambda=\lambda_{n}=a \sqrt[4]{\omega_{n}^{2}} ; a^{4}=(\rho A / E I) l^{4} .
$$

\subsection{Finite element method}

Numerical examples are solved by means of the finite element method, using the software ALGOR 23.1 [24]. The column and the beam are divided into 100 beams elements respectively, each beam element with three degrees of freedom.

The internal hinge elastically restrained was modeled by a very small beam element, 300 times smaller than the length of the beam. The moment of inertia of the section was varied in order to obtain stiffness values that are equivalent to the stiffness constants of the spring connecting the two sections of the lintel.

\subsection{Experimental model}

An experimental device was built to verify the analytical and numerical models developed. A frame of two uniform members of equal length $l$ (Figure 2) was tested under different boundary conditions (clamped and free) at the lower end of its vertical member $\left(x_{1}=0\right)$. The other end $\left(x_{3}=1\right)$ is clamped. The presence of internal hinge is not considered.

The magnitudes of the frame are: $l=0.50 \mathrm{~m}, A=4.064 \times 10^{-5} \mathrm{~m}^{2}, I=3.468 \times 10^{-11} \mathrm{~m}^{4}$ and $E=2.1 \times 10^{6} \mathrm{~kg} / \mathrm{cm}^{2}$.

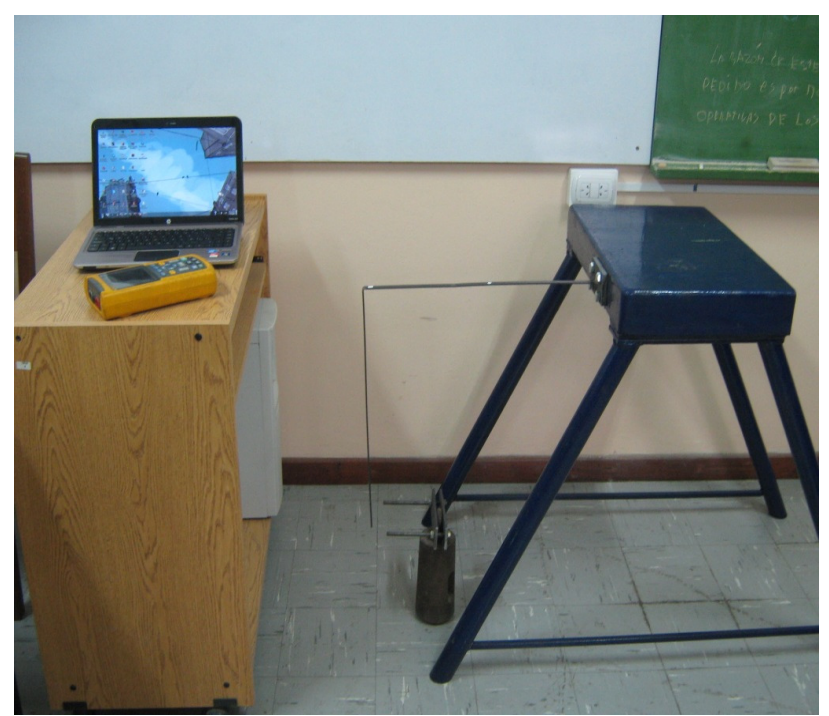

Figure 2. Experimental set-up for clamped-free model.

In order to measure the natural frequencies, an optical proximity sensor was used.

Figure 3 shows the spectrum of the first natural frequency of the frame clampedclamped and clamped-free respectively. 


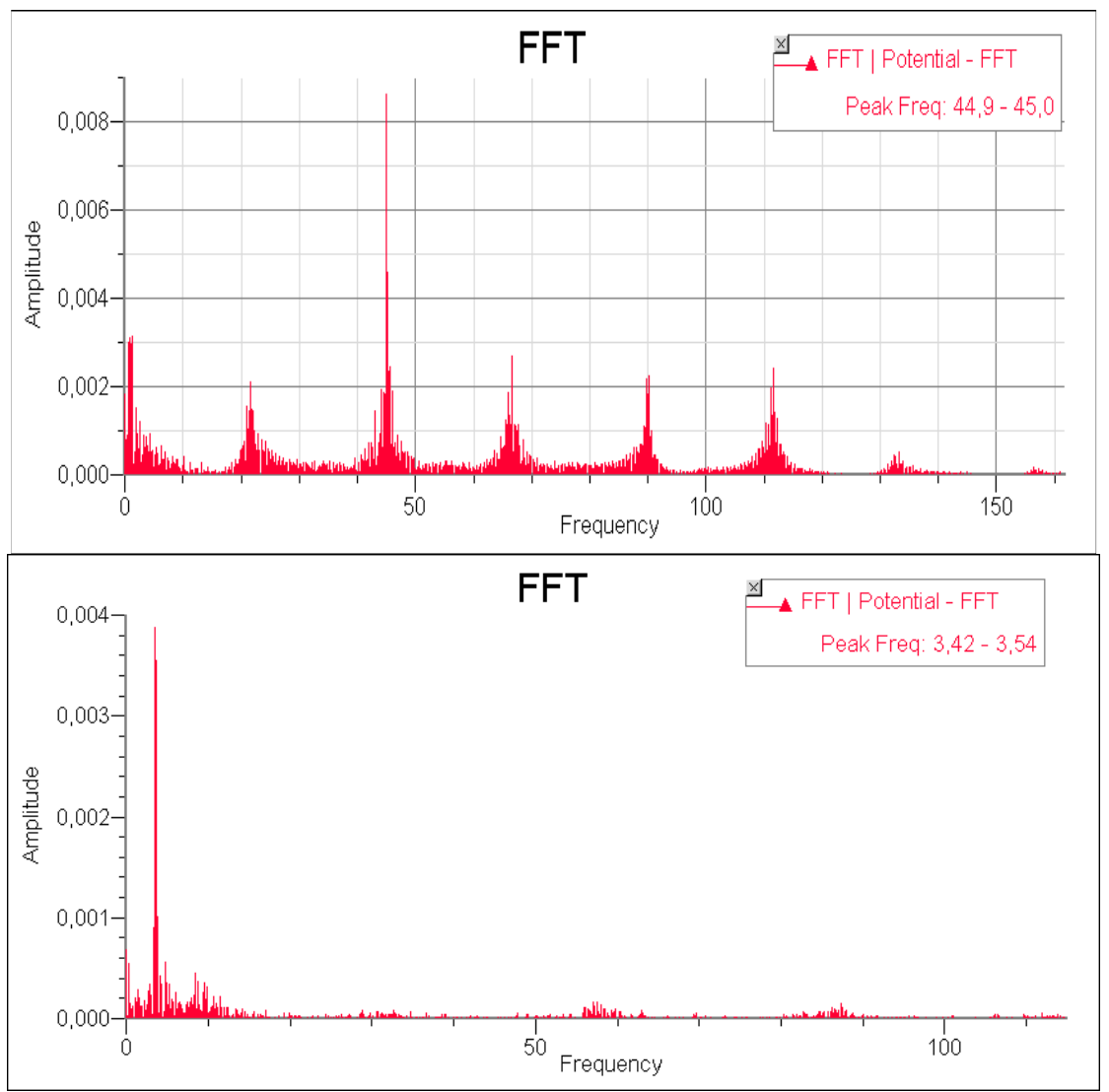

Figure 3. Spectrum of the first natural frequency.

\section{NUMERICAL RESULTS}

\subsection{Validation of the model}

The proposed approach allows solving many special cases. Some numerical examples are developed. In all of them it is supposed that the whole frame is of the same material and have equal stiffness:

$$
\begin{gathered}
v_{E I i}=\frac{(E I)_{i}}{E I}=1 ; v_{\rho A i}=\frac{(\rho A)_{i}}{\rho A}=1 ; i=1,2,3 . \\
v_{E I i}=\frac{(E I)_{i}}{E I}=1, v_{\rho A i}=\frac{(\rho A)_{i}}{\rho A}=1, \quad i=1,2,3
\end{gathered}
$$

The relation between lengths is constant, $l_{1}=l_{2}+l_{3}$, while the relative lengths of the lintel, $l_{2}$ and $l_{3}$ may change.

Table 1 presents the first three coefficients of natural frequency of vibration of a frame clamped-clamped without internal hinge. Both members of the frame have the same length $l$. The values without internal hinge were obtained by the finite element method (FEM) [24] and were compared with those calculated by Albarracín and Grossi [15]. 
Table 1. Frequency coefficients: $\lambda_{i}=a \sqrt[4]{\omega_{n}^{2}}, a^{4}=(\rho A / E I) l^{4}$, clamped-clamped frame without internal hinge

\begin{tabular}{cccc}
\hline & $\lambda_{1}$ & $\lambda_{2}$ & $\lambda_{3}$ \\
\hline Analytical & 3.9234 & 4.6605 & 7.0430 \\
FEM & 3.9248 & 4.7239 & 7.0574 \\
{$[15]$} & 3.9225 & 4.7142 & 7.0376 \\
\hline
\end{tabular}

Figure 4 shows the first three mode shapes for an L-frame clamped-clamped without internal hinge. They correspond to the frequency coefficients presented in Table 1.

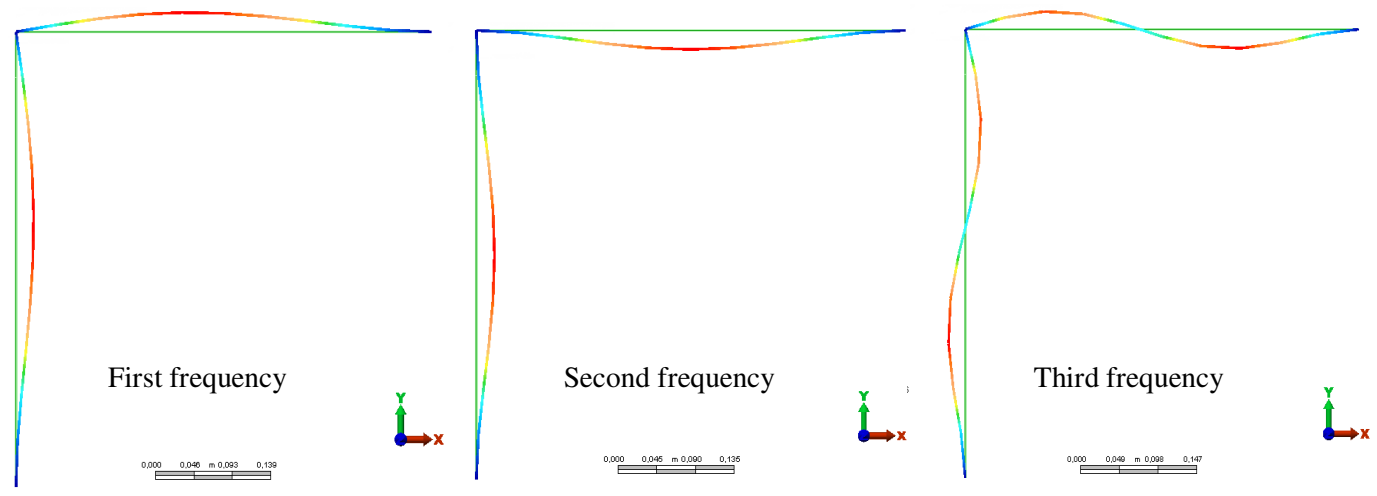

Figure 4. Mode shapes of clamped-clamped frame without internal hinge.

Table 2 shows the frequency parameters of an L-frame without internal hinge, when the spring constants at the outer end $T_{x}, T_{y}$ and $R_{x y}$ take three different values: 0,10000 and $\rightarrow \infty$.

Table 2. Frequency coefficients for L-frame without hinge $\left(T_{x},=T_{y}=R_{x y}\right)$

\begin{tabular}{|c|c|c|c|c|c|c|c|c|}
\hline \multirow[b]{2}{*}{$\begin{array}{c}T_{x}=T_{y} \\
=R_{x y}\end{array}$} & \multicolumn{2}{|l|}{$\left(f_{1}\right)$} & \multicolumn{2}{|l|}{$\lambda_{1}$} & \multicolumn{2}{|c|}{$\lambda_{2}$} & \multicolumn{2}{|c|}{$\lambda_{3}$} \\
\hline & $\begin{array}{c}\operatorname{Exp} \\
\lambda_{1}=\end{array}$ & $\begin{array}{l}\text { nental } \\
\sqrt{\omega_{1}^{2}}\end{array}$ & Analytical & $\mathrm{MEF}$ & Analytical & MEF & Analytical & MEF \\
\hline 0 & $\begin{array}{l}(3.51 \\
\mathrm{Hz})\end{array}$ & 1.0960 & 1.0919 & 1.0890 & 1.8609 & 1.8612 & 3.9057 & 3.9059 \\
\hline 10000 & -- & -- & 3.3980 & 3.4089 & 3.7011 & 3.7120 & 4.4729 & 4.4838 \\
\hline$\rightarrow \infty$ & $\begin{array}{l}(45 \\
\mathrm{Hz})\end{array}$ & 3.9123 & 3.9234 & 3.9248 & 4.6603 & 4.7239 & 7.0430 & 7.0574 \\
\hline
\end{tabular}

As it can be seen in the Tables, all the results are consistent.

\subsection{Analysis of the model in presence of a crack}

For further analysis, the presence of a crack in the lintel is introduced. The crack is modeled as a hinge with a rotational spring using the formula proposed by Chondros et al. [22] for the crack flexibility. These authors proposed to model a crack as a continuous flexibility using the displacement field in the vicinity of the crack, found with fracture mechanics methods. The crack flexibility is assumed as: 


$$
\alpha_{C}=\frac{6 \pi\left(1-v^{2}\right) h}{E I} I_{C}\left(h_{c} / h\right)
$$

where $h$ is the height of the cross-section, $v$ is the Poisson ratio and $h_{c}$ is the crack depth. $I_{c}$ is defined by the expression:

$$
\begin{gathered}
I_{c}(z)=0.6272 z^{2}-1.04533 z^{3}+4.5948 z^{4}-9.973 z^{5}+20.2948 z^{6}- \\
-33.0351 z^{7}+47.1063 z^{8}-40.7556 z^{9}+19.6 z^{10}
\end{gathered}
$$

with $z=h_{c} / h$.

Assuming like [22] that the effect of the supposed crack affects only in its neighborhood, the lintel can be treated as two uniform beams of length $l_{2}$ and $l_{3}$, connected by a rotational spring of local rigidity $R_{m}=1 / \alpha_{C}$ at the crack position.

Table 3 depicts values of coefficients $\lambda_{i}$, obtained by the analytical procedure, when the same type of the crack is considered in different positions of the lintel beam for a clamped-

\begin{tabular}{|c|c|c|c|}
\hline$l_{2} / l_{1}$ & $\lambda_{1}$ & $\lambda_{2}$ & $\lambda_{3}$ \\
\hline $1 / 3$ & 3.5154 & 4.4646 & 5.9115 \\
\hline $1 / 2$ & 3.9179 & 4.6653 & 6.1562 \\
\hline $2 / 3$ & 3.8811 & 4.5467 & 6.7124 \\
\hline
\end{tabular}
clamped frame. The assumed value for $h_{c}$ is $2 / 3 h$.

Table 3. Frequency coefficients $\lambda_{i}$ of the frame for different positions of the crack.

As it can be observed, the position of the crack in the middle of the lintel influences very little the first two frequencies of vibration. That is expectable, since the solid undamaged model has an inflexion point near this position in its two first modes of vibration (See Figure 4).

Figures 5, 6 and 7 show the modal shapes for the first three frequency of vibration for different positions of the crack (the arrow indicates the position of the crack). 


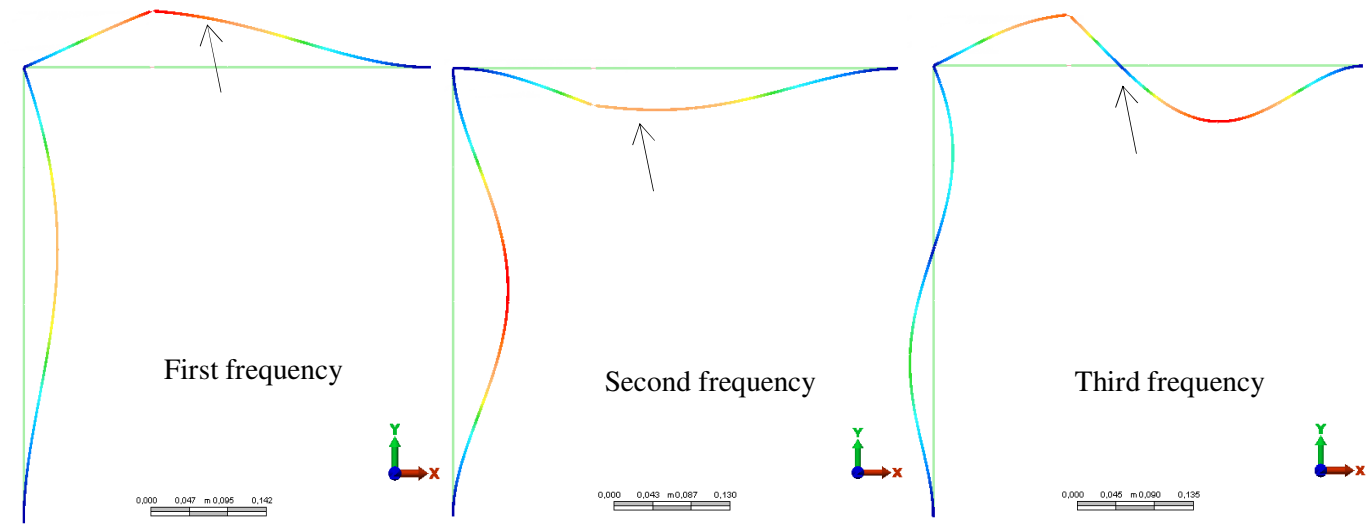

Figure 5. Mode shape of the frame with varying elastically hinge on the lintel, for $v_{l i}=1$, $l_{2}=1 / 3 l_{1} ; v_{l i}=1, T x=T y=R x y \rightarrow \infty, v_{E I(2)}=v_{E I(3)}=1 ; v_{\rho A(2)}=v_{\rho A(3)}=1 ; T=R=0 ; R m=700$.
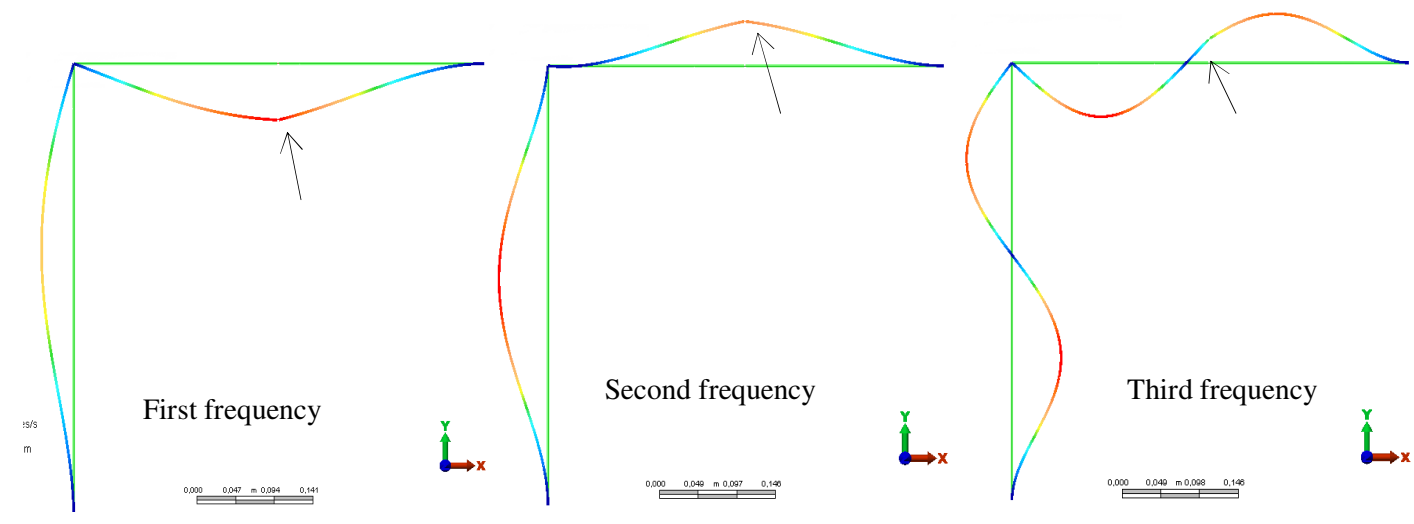

Figure 6. Mode shape of the frame with elastically hinge on the lintel, for for $v_{l i}=1$, $l_{2}=1 / 2 l_{1} ; v_{l i}=1, T x=T y=R x y \rightarrow \infty, v_{E I(2)}=v_{E I(3)}=1 ; v_{\rho A(2)}=v_{\rho A(3)}=1 ; T=R=0 ; R m=700$.
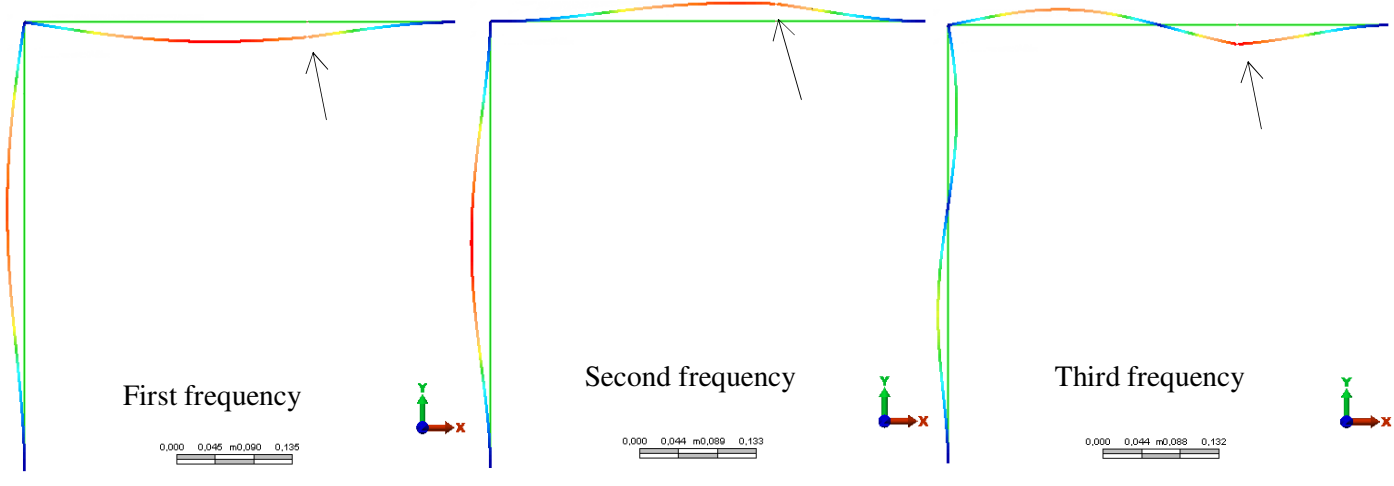

Figure 7. Mode shape of the frame with elastically hinge on the lintel, for for $v_{l i}=1$, $l_{2}=2 / 3 l_{1} ; v_{l i}=1, T x=T y=R x y \rightarrow \infty, v_{E I(2)}=v_{E I(3)}=1, v_{\rho A(2)}=v_{\rho A(3)}=1 ; T=R=0 ; R m=700$. 


\section{CONCLUSIONS}

In this paper the method of separation of variables combined with the variational calculation technique is used to deal with a difficult elastodynamics problem: the vibration of a plane frame with additional complexities as elastic external and internal elastic supports. The Euler-Bernoulli beam theory including the axial deformation is considered for each member of the structure. The values obtained with the proposed analytical approach are satisfactorily compared with particular cases available in the literature and with those acquired by means of a MEF code. In some cases, an experimental verification is performed. Values of the first natural frequencies of vibration and the corresponding modal shapes are presented. The model, also allows analyzing the influence of a crack in the dynamical behavior of the frame.

\section{Acknowledgements}

The present study has been sponsored by the Universidad Nacional del Sur, UNS, and the Consejo Nacional de Investigaciones Científicas y Técnicas, CONICET. It was developed in the Departamento de Ingeniería and Instituto de Mecánica Aplicada, IMA. The authors are indebted to Professor Ricardo Grossi for his valuable suggestions and to Salvador La Malfa, CONICET, and Osvaldo Alvarez ; Comisión de Investigaciones Científicas de la Provincia de Buenos Aires, CIC, for their contrbution in the construction of the model and experimental tests.

\section{REFERENCES}

[1] Laura P A. A., Valerga de Greco, B. H., Filipich C. A., "In-plane vibrations of frames carrying concentrated masses". Journal of Sound and Vibration,. 17(3), 447-458, 1987.

[2] Warburton, G.B., "The Dynamical Behaviour of Structures". (2nd edition), Pergamon Press Ltd., Oxford, 1976.

[3] Blevins R., "Formulas for Natural Frequency and Mode Shape", Krieger Melbourne, FL, 1993.

[4] Clough R. W., Penzien J. “Dynamics of Structures”. McGraw!Hill New York. 1975.

[5] Timoshenko S., Young D.H., "Vibration Problems in Engineering". Van Nostrand, Princeton, New York, 1956.

[6] Karnosky I. A., Lebed O. I., "Free vibrations of beam and frames". McGraw-Hill. New York, 2004

[7] Lin H.P., Ro, J. "Vibration analysis of planar serial-frame structures", Journal of Sound and Vibration 262, 1113-1131, 2003.

[8] Wu J.J., "Use of the elastic-and-rigid-combined beam element for dynamic analysis of a 
two-dimensional frame with arbitrarily distributed rigid beam segments". Applied Mathematical Modelling 35, 1240-1251, 2011.

[9] Mei C., "Wave control of vibrations in multi-story planar frame structures based on classical vibration theories". Journal of Sound and Vibration, 330, 5530-5544, 2011.

[10] Filipich C.P., Laura P. A. A., "In-plane vibrations of portal frames with end supports elastically restrained against rotation and translation". Journal of Sound and Vibration.117, 467-476, 1987.

[11] H. Bang, "Analytical solution for dynamic analysis of a flexible L-shaped structure". Journal of Guidance, Control and Dynamics, 19 (1), 248-250, 1996.

[12] Gürgöze M., "Comment on 'Analytical solution for dynamic analysis of a flexible Lshaped structure"”. Journal of Guidance, Control and Dynamics, 21 (2), 359, 1998.

[13] Oguamanam D.C.D., Hasen J.S., Heppler G. R., "Vibration of arbitrarily oriented twomember open frame with tip mass". Journal of Sound and Vibration. 209; 651-669,1998.

[14] Heppler G. R., Oguamanam D.C.D., Hasen J.S., "Vibration of a two-member open frame”. Journal of Sound and Vibration. 263, 299-317, 2003.

[15] Albarracín C. M., Grossi R. O., "Vibrations of elastically restrained frames", Journal of Sound and Vibration. 285, 467-476, 2005.

[16] Lee H. P., Ng T. Y., "In-plane vibrations of planar frame structures". Journal of Sound and Vibration, 172, 420-427, 1994.

[17] Wang, C.Y., Wang, C.M., "Vibrations of a beam with an internal hinge". International Journal of Structural Stability and Dynamics. 1, 163-167, 2001.

[18] Lee Y.Y., Wang C.M., Kitipornchai S., "Vibration of Timoshenko beams with internal hinge". Journal of engineering Mechanics. 129, 293-301, 2003.

[19] Chang, T.P., Lin, G.L., Chang, E., "Vibrations analysis of a beam with an internal hinge subjected to a random moving oscillator". International Journal of Solid and Structures. 43, 6398-6412, 2006.

[20] Grossi, R.O., Quintana, M. V., The transition conditions in the dynamics of elastically restrained beams". Journal of Sound and Vibration, 316, 274-297, 2008.

[21] Quintana V., Raffo J. L., Grossi R. O., "Eigenfrequencies of generally restrained Timoshenko beam with an internal hinge". Mecánica Computacional XXIX, 2499-2516, 2010.

[22] Chondros, T.G., Dimarogonas, A.D. y Yao, J., "A continuous cracked beam vibration theory". Journal of Sound and Vibration, 215, 17-34, 1998. 
[23] Wolfram MATHEMATICA 8 software. Version 8000. Copyright 1988-2010.

[24] ALGOR software. Version 23.01. 2009. 